\title{
Regulation of neuronal toxicity of $\beta$-amyloid oligomers by surface ATP synthase
}

\author{
SANLI XING ${ }^{*}$, DINGZHU SHEN* ${ }^{*}$ CHUAN CHEN, JIAN WANG, TE LIU and ZHIHUA YU \\ Shanghai Geriatric Institute of Chinese Medicine, Shanghai University of Traditional Chinese Medicine, \\ Shanghai 200031, P.R. China
}

Received May 28, 2013; Accepted October 7, 2013

DOI: $10.3892 / \mathrm{mmr} .2013 .1722$

\begin{abstract}
Alzheimer disease (AD) is characterized by the accumulation of amyloid- $\beta$ (A $\beta)$ protein and intracellular neurofibrillary tangles. Previous studies have shown that $A \beta$ aggregation is one of the most important initiating factors in the pathogenesis of $\mathrm{AD}$. Oligomers of $\mathrm{A} \beta$ cause neurotoxicity, synaptic dysfunction and memory impairments that underlie AD. An increasing number of studies have shown that oligomeric $A \beta$ may bind with a number of surface proteins to mediate its neuronal toxicity. Previously, it was shown that ATP synthase is present on the cell surface and binds with oligomeric A $\beta$. In the present study, ATP synthase was confirmed to be present on the surface of neurons and oligomeric $A \beta$ was observed to induce neuron damage and expression of amyloid precursor protein (APP) and Fe65 increase. Results showed that inhibition of surface ATP synthase may reduce the neuronal damage by LDH release assay and decrease APP and Fe65 expression by immunofluorescence and western blot analysis. These results confirmed that the cell surface ATP synthase is a binding protein for $A \beta$ on neural cells and suggested that the surface ATP synthase may be involved in the neurotoxic effects of oligomeric $A \beta$ and may be an intervening target of pathogenesis of AD.
\end{abstract}

\section{Introduction}

Alzheimer disease (AD) is a progressive neurodegenerative disease. The pathological features of $\mathrm{AD}$ include senile plaque deposits and neurofibrillary tangles. The major constituent of senile plaques is amyloid- $\beta$ (A $\beta)$ peptides, which are

Correspondence to: Mr. Chuan Chen, Shanghai Geriatric Institute of Chinese Medicine, Shanghai University of Traditional Chinese Medicine, 365 South Xiangyang Road, Shanghai 200031, P.R. China E-mail: article_chenchuan@163.com

\section{*Contributed equally}

Key words: Alzheimer disease, oligomer A $\beta$, surface ATP synthase, cultured neurons, neuronal toxicity generated as cleavage fragments by the action of $\gamma$ and $\beta$ secretase on the amyloid precursor protein (APP) metabolism. Due to their inherently disordered and 'sticky' nature, the resulting $A \beta$ peptides easily aggregate into oligomers, then fibrils and mature plaques in the brain (1). A previous study suggested that $A \beta$ oligomers are the most toxic form of $A \beta$ peptide and are critical in inducing cognitive impairment and synaptic dysfunction (2), however, the cell mechanisms of $A \beta$ oligomer-mediated neurotoxicity are poorly defined. Experimental evidence supports the hypothesis that the disease process starts with the binding of oligomeric assemblies of $A \beta$ to proteins on the surface of nerve cells (3). The identity of the molecules to which oligomers of $A \beta$ bind to remains largely enigmatic. A number of binding proteins of $\mathrm{A} \beta$ have been identified on the neuron cell surface, including the $\mathrm{N}$-methyl-D-aspartate receptor (4), integrins and the $\alpha 7$ nicotinic acetylcholine receptor (5).

ATP synthase, traditionally studied in the mitochondria, where it generates the majority of cellular ATP, has also been detected on the plasma membranes of several cell types $(6,7)$. The ecto-ATP synthase serves as a multi-ligand receptor to regulate specific biological effects (8-10). Therefore, it was valuable to study the properties of ATP synthase on the neuronal surface, which have yet to be clearly elucidated. In a previous study, it was found that the presence of ATP synthase on the neuronal surface is responsible for the production of extracellular ATP (11) and that the cell surface ATP synthase $\alpha$ is a binding protein for $A \beta$ on neural cells. Previous observations have demonstrated a novel function for $A \beta$ in regulating ATP synthase activity through interaction with the $\alpha$ subunit of ATP synthase (12).

In the present study, the effect of the exogenous addition of oligomeric $\mathrm{A} \beta$ on neuronal cells and its effect on the APP/Fe65 signaling pathway was observed. ATP synthase was confirmed to be located on the surface of neuron cells and oligomeric $\mathrm{A} \beta$ was observed to induce neuron damage by $\mathrm{LDH}$ release, which originated from the breakdown in the integrity of the plasma membrane. From these observations, the expression of APP and Fe 65 following oligomeric A $\beta$ treatment was studied. Results showed that inhibition of the surface ATP synthase may reduce the neuronal damage and decrease APP and Fe65 expression. These results confirmed that the cell surface ATP synthase has a pathophysiological role in $\mathrm{A} \beta$-induced neuronal toxicity. 

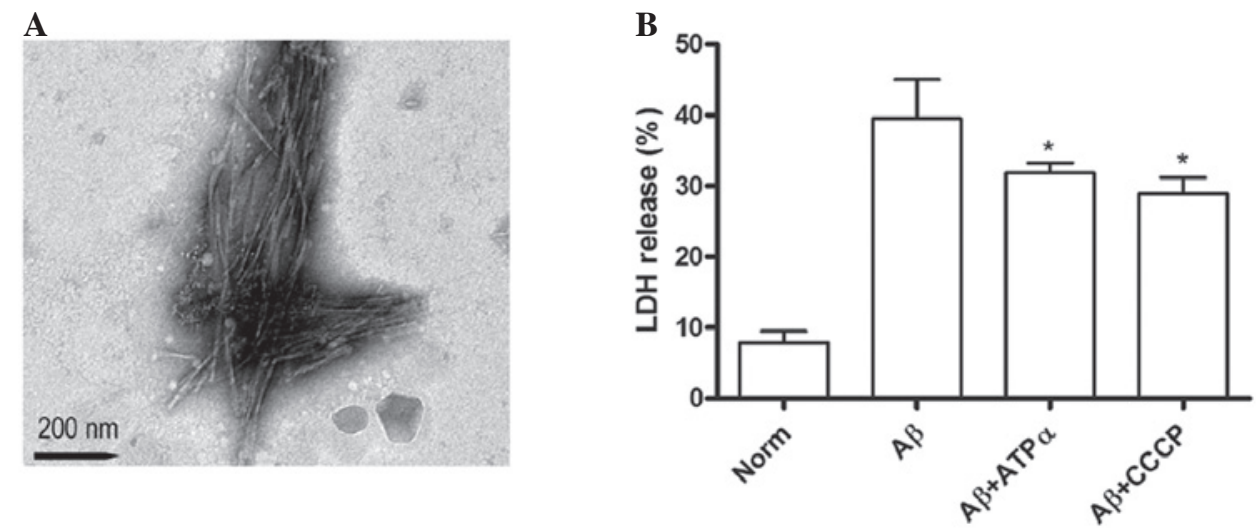

Figure 1. (A) Aggregation of A $\beta$ was determined by electron microscopy and (B) activity of LDH released by $\mathrm{A}_{\beta 1-40}$, treated with anti-ATP $\alpha$ antibody or CCCP against cytotoxicity. Subsequent to culturing primary cortical neurons for 9 days, neurons were treated with CCCP, anti-ATP $\alpha$ antibody in the presence of $A \beta_{1-40}$ for $8 \mathrm{~h}$, the supernatant of the groups (control, $A \beta_{1-40}, A \beta_{1-40}+$ ATP $\alpha$ antibody, $A \beta_{1-40}+$ CCCP groups) were assayed by the LDH release rate. The data are expressed as mean $\pm \mathrm{SD}, \mathrm{n}=4 .{ }^{*} \mathrm{P}<0.05$ vs. $\mathrm{A} \beta_{1-40}$ group following the Student's t-test. $\mathrm{A} \beta$, amyloid- $\beta$.

\section{Materials and methods}

Cell culture. Cortices of embryos were obtained from pregnant Sprague-Dawley E16-E17 rats (Experimental Animal Center of Shanghai University of Traditional Chinese Medicine) and dissociated with $0.125 \%$ trypsin for $10 \mathrm{~min}$ at $37^{\circ} \mathrm{C}$, then fetal bovine serum (FBS) was added to halt trypsinization. Cell suspensions were filtered through stainless steel mesh filter and centrifuged for $6 \mathrm{~min}$ at $555 \mathrm{x}$ g. The cells were plated onto poly-L-lysine-coated plates or dishes according to the manufacturer's instructions with Dulbecco's modified Eagle's medium (Gibco-BRL, Carlsbad, CA, USA) and supplemented with $10 \%$ FBS. Following $24 \mathrm{~h}$, the medium was replaced with Neurobasal medium containing B27 supplement. Cultures were maintained for 8-10 days. Experiments were performed according to the Guide for the Care and Use of Medical Laboratory Animals (Ministry of Health, China, 1998) and the guidelines of the Shanghai University of Traditional Chinese Medical Laboratory Animal Care and Use Committee.

Preparation of aggregated $A \beta_{1-40}$ and electron microcopy. Aggregates of $A \beta_{1-40}$ were produced by dissolving a peptide in $\mathrm{ddH}_{2} \mathrm{O}$ to $700 \mu \mathrm{M}$, immediately diluting in PBS to $350 \mu \mathrm{M}$ and incubating at $37^{\circ} \mathrm{C}$ for 7 days. The aggregated states were checked by electron microscopy. Briefly, $A \beta_{1-40}$ solution was absorbed onto a carbon-coated copper grid and stained negatively with $1 \%$ phosphotungstic acid. Following drying, images were captured by electron microscopy (JEM-2100, JEOL, Tokyo, Japan) operating at $120 \mathrm{kV}$.

$L D H$ release assay. Neurotoxicity of $\mathrm{A} \beta$ was evaluated by analyzing LDH content in culture medium. Neuronal cells were seeded in 96-well plates and 1\% Triton X-100 was used as a positive control. Supernatant $(50 \mu \mathrm{l})$ was transferred to a fresh 96-well plate and an equal volume of freshly prepared reaction mixture was added at $37^{\circ} \mathrm{C}$ for $10 \mathrm{~min}$ and $0.1 \mathrm{M}$ citric acid $20 \mu \mathrm{l}$ was added to end the reaction. The absorbance was measured at $570 \mathrm{~nm}$.

Immunofluorescence staining. The mitochondria of primary cultured neurons on coverslips were first labeled by incubating with a mitochondrial dye, the Mitotracker (GenMed Scientifics Inc., Shanghai, China), then the cells were fixed with $4 \%$ paraformaldehyde for $30 \mathrm{~min}$ at room temperature and blocked in 5\% BSA for $30 \mathrm{~min}$ with or without $0.2 \%$ Triton X-100. The cells were incubated with the primary antibodies with or without $0.2 \%$ Triton X-100, including anti-ATP synthase $\alpha$, anti-APP-C (both 1:200; BD Biosciences, San Jose, CA, USA) and anti-Fe65 (1:200; Santa Cruz Biotechnology, Inc., Dallas, TX, USA), overnight at $4^{\circ} \mathrm{C}$. After being washed three times with $0.01 \mathrm{M}$ PBS, the cells were incubated with FITC or Texas Red-conjugated secondary antibodies (1:200; Santa Cruz Biotechnology, Inc.) at $37^{\circ} \mathrm{C}$ for $1 \mathrm{~h}$. For nuclear staining, the cells were incubated with $2 \mu \mathrm{g} / \mathrm{ml}$ DAPI for $5 \mathrm{~min}$ at $37^{\circ} \mathrm{C}$, washed three times and fluorescence signals were detected by confocal laser scanning microscopy (TCS-SP2; Leica, Wetzlar, Germany) or observed under a fluorescence microscope (BX51; Olympus, Tokyo, Japan).

Western blot analysis. Total protein was extracted and the concentration in samples was determined by Micro-BCA protein assay (Pierce Biotechnology Inc., Rockford, IL, USA). Samples were resolved by SDS-PAGE and transferred onto polyvinylidene fluoride membranes. The membranes were incubated with primary antibodies anti-APP-C $(1: 1,000)$, anti-Fe65 (1:1,000) and anti-GADPH (1:5,000; all Abcam, Cambridge, MA, USA) at $4^{\circ} \mathrm{C}$ overnight. Following washing, the membranes were incubated with horseradish peroxidase-conjugated secondary antibodies for $1 \mathrm{~h}$ at room temperature. Blots were visualized by enhanced chemiluminescence.

Statistical analysis. Statistical analysis was performed using GraphPad Prism version 5 (GrahPad Software, San Diego, CA, USA). Measurement data are expressed as mean \pm SD. Differences were assessed using the Student's t-test for comparisons. $\mathrm{P}<0.05$ was considered to indicate a statistically significant difference.

\section{Results}

Effect of $A \beta$ on the viability of primary cortical neuron by ATP synthase. To confirm the oligomer state of $\mathrm{A} \beta$ aggregates, 


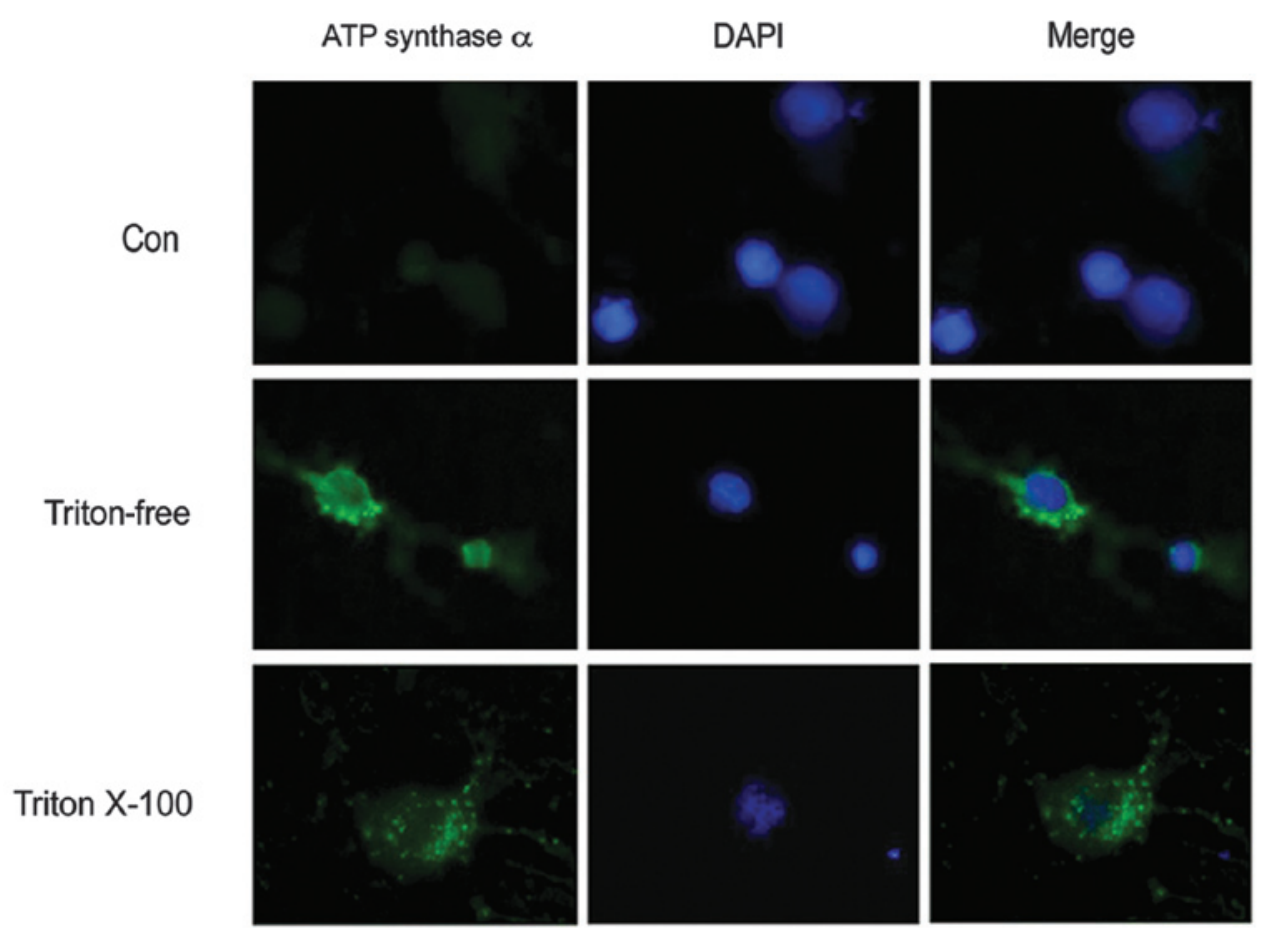

Figure 2. ATP synthase is expressed on the surface of primary cultured neurons. Immunofluorescent staining of ATP synthase and DAPI on the plasma membrane of neurons. Neurons were stained with anti-ATP synthase $\alpha$ antibody with or without Triton X-100, and neurons without anti-ATP synthase $\alpha$ antibody served as the control group.
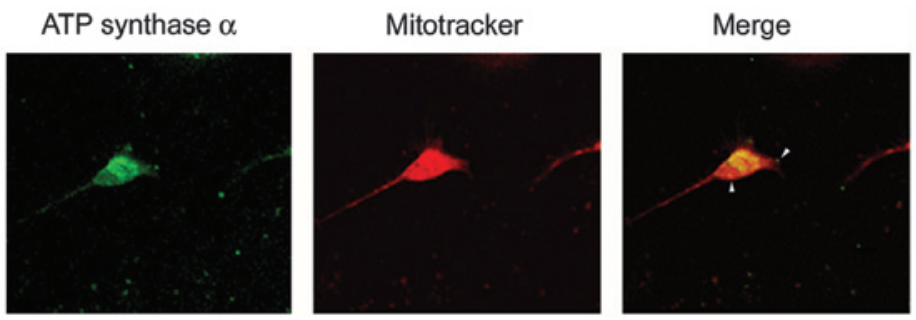

Figure 3. ATP synthase is expressed on the plasma membrane of primary cultured neurons. Neurons prelabeled with Mitotracker were stained with anti-ATP synthase $\alpha$ omitting Triton X-100.

electron microscopy was used to probe the aggregation. Robust fibrils were primarily observed (Fig. 1A). Increasing activity of LDH released from cells into culture medium also indicated the damage to neurons. LDH activity was assayed in the supernatant of the control, exposed to $\mathrm{A} \beta_{1-40}(5 \mu \mathrm{mol} / \mathrm{l})$ and treated with anti-ATP synthase $\alpha$ antibody $(0.25 \mu \mathrm{g} / \mathrm{ml})$ or CCCP $(1 \mu \mathrm{g} / \mathrm{ml})$ in the presence of $\mathrm{A} \beta$ groups. The results showed that $\mathrm{A} \beta$ treatment promoted more $\mathrm{LDH}$ release compared with the control group. Furthermore, the data suggested that groups exposed to anti-ATP synthase $\alpha$ antibody or CCCP in the presence of $\mathrm{A} \beta$ had significantly lower leakage of $\mathrm{LDH}$, indicating that the cytotoxicity of $\mathrm{A} \beta$ on the neuron may be occurring through the neuronal surface ATP synthase pathway (Fig. 1B).

ATP synthase is located on the cell surface of primary cultured neurons. In a previous study (11) it was suggested that the expression of the ATP synthase complex is located on the neuronal surface. In the present study, the primary cultured neurons were immunostained with anti-ATP synthase $\alpha$ antibody with or without Triton X-100. The results demonstrated that subunits of ATP synthase were distributed on the neuronal cell body as well as on the surface (Fig. 2). To confirm that the expression of ATP synthase complex is on the neuronal surface, live neurons prelabeled with Mitotracker were immunostained with an anti-ATP synthase $\alpha$ antibody. Triton X-100, which is commonly used to permeabilize cells, was omitted to decrease the antibody in the neuron. The results showed that the $\alpha$ subunits of ATP synthase appeared as a punctate distribution on the neuronal surface (Fig. 3).

$A \beta$ inhibits the APP expression levels through neuronal surface ATP synthase. In the current study, primary neuronal cultures exposed to A $\beta$ led to an increase in APP expression levels. The adaptor protein Fe65 has been shown to mediate APP metabolism and increase $A \beta$ production, thus the present study showed that exposure to $A \beta$, led to an increase in Fe65 levels. However, immunofluorescence studies showed that groups exposed to the anti-ATP synthase $\alpha$ antibody or CCCP 


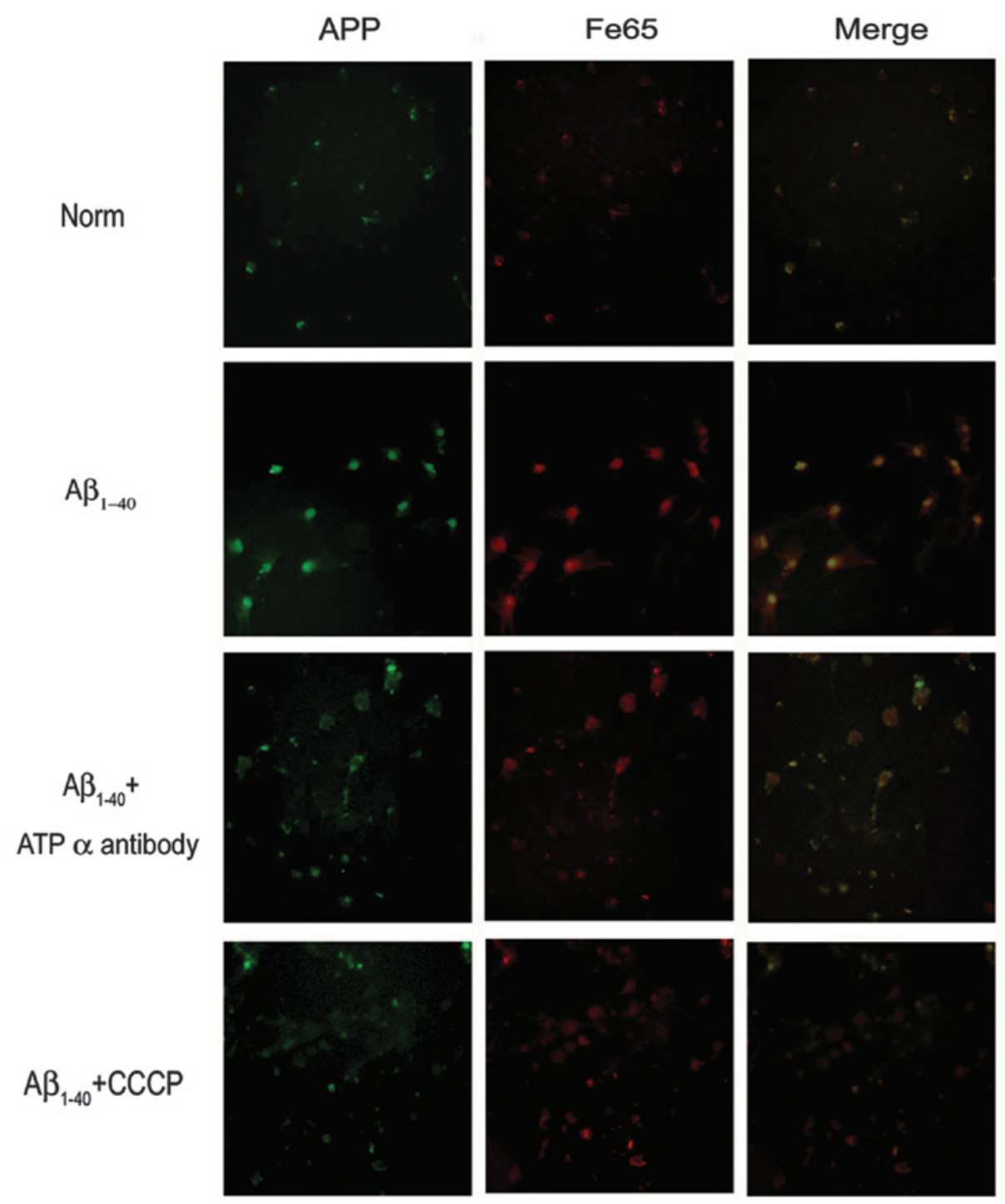

Figure 4. Effect of surface ATP synthase on A $\beta$-induced neuronal dystrophy associated with increased APP and Fe65. Cortical cultures were treated with anti-ATP $\alpha$ antibody (A $\beta_{1-40}+$ ATP synthase $\alpha$ ), CCCP (ATP synthase inhibitor, A $\beta_{1-40}+\mathrm{CCCP}$ ) in the presence of A $\beta_{1-40}$ for $8 \mathrm{~h}$ and without any treatment as the norm group and only with $A \beta_{1-40}$ treatment as the $A \beta_{1-40}$ group. $A \beta$, amyloid- $\beta$; APP, amyloid precursor protein.
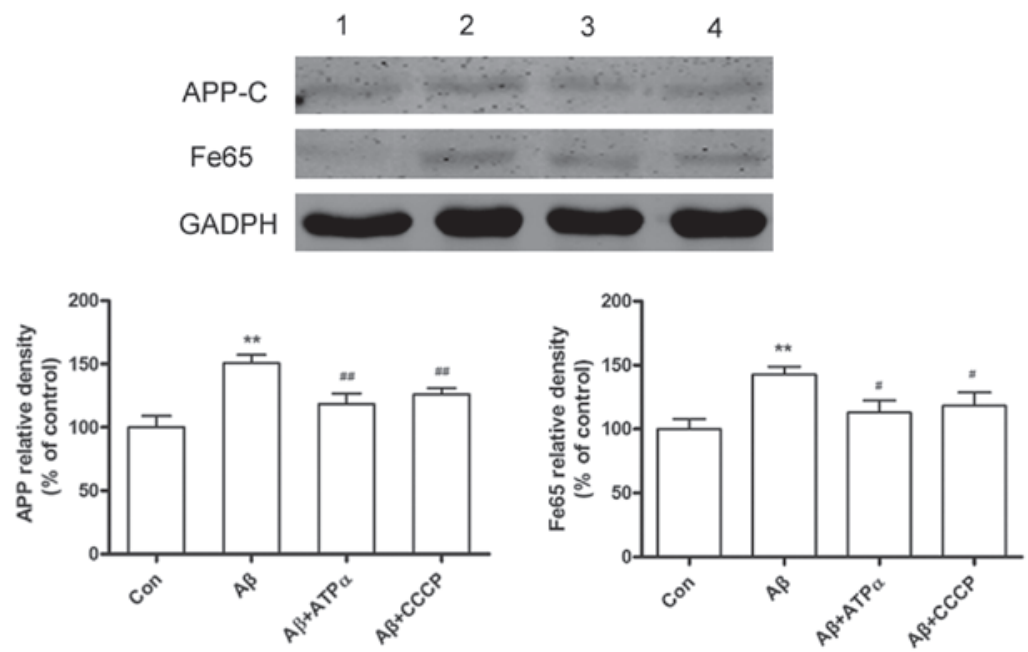

Figure 5. A $\beta$ induced the changes of APP and Fe65 affected by the surface ATP synthase. The primary cultured neurons were treated without (Lanes 1 , control group) or with $\mathrm{A} \beta_{1-40}$ (Lane 2, group treated with $\mathrm{A} \beta_{1-40}$ only) in the presence of ATP synthase $\alpha$ antibody (Lane 3, group treated with A $\beta_{1-40}$ and anti ATP $\alpha$ antibody) or CCCP (Lane 4, group treated $\mathrm{A} \beta_{1-40}$ and with CCCP). Protein levels of APP and Fe65 were assayed by western blotting. Results showed that anti-ATP synthase $\alpha$ antibody and CCCP (ATP synthase inhibitor) inhibited A $\beta_{1-40}$ induced enhancement in APP and Fe65 proteins (n=3). * P $<0.01$ vs. control group; ${ }^{\# \#} \mathrm{P}<0.01$ vs. $\mathrm{A} \beta_{1-40}$ group; ${ }^{\#} \mathrm{P}<0.05$ vs. $\mathrm{A} \beta_{1-40}$ group. $\mathrm{A} \beta$, amyloid $\beta ; \mathrm{APP}$, amyloid precursor protein. 
in the presence of A $\beta$ had significantly decreased APP and Fe65 levels (Fig. 4). To determine the inhibition of neuronal surface ATP synthase $\alpha$, the APP and Fe65 levels were analyzed following pretreatment with the ATP synthase $\alpha$ antibody or CCCP in the presence of $\mathrm{A} \beta$ on cultured neurons by western blot analysis. Results showed that the cytotoxicity of $A \beta$ on the primary cultured neuron was regulated by neuronal surface ATP synthase $\alpha$ (Fig. 5).

\section{Discussion}

$\mathrm{A} \beta$ is the primary component of amyloid deposits in $\mathrm{AD}$, which is capable of interacting with a number of molecular partners and regulating its activity $(13,14)$. The cell surface is the first site of interaction between extracellular $A \beta$ and neurons. Our previous study (11) showed that ATP synthase was present on the surface of cultured neural cells and demonstrated that the $\alpha$-subunit of ATP synthase was located in the senile plaques of APP/PS1 transgenic mice and co-labeled with A $\beta$. Cell surface ATP synthase acts to bind a number of ligands and to trigger hydrolysis or synthesis of ATP, lipid metabolism and cell death. In contrast to the studies of surface ATP synthase on hepatocytes and endothelial cells $(15,16)$, ATP synthase on neurons has been less studied. For instance, the $\alpha$-subunit of ATP synthase not only co-deposits with neurofibrillary tangles in Alzheimer's disease, but also binds with amyloid- $\beta$ peptide and the amyloid precursor protein and it appears that ecto-ATP synthase may be involved in neurodegeneration $(17,18)$.

APP is an integral membrane protein from which the $\beta$-amyloid peptide is generated. APP was hypothesized to be involved in the signal transduction processes, due to its transmembrane structure (19). The Fe65 gene is primarily expressed in the neurons of specific regions of the mammalian nervous system and encodes a protein containing two types of protein-protein interaction domains: the WW domain and the phosphotyrosine interaction/phosphotyrosine binding (PID/PTB) domain. The PID/PTB domains were demonstrated to interact with the intracellular domain of APP (20). By overexpression or knockdown, Fe65 has been shown to modulate APP metabolism, increase APP translocation to the plasma membrane, which was accompanied by an increase in $A \beta$ production and sAPP secretion $(21,22)$. Thus, it was hypothesized that the APP changes may affect the interaction with Fe65.

The current observations suggest that $A \beta$ affects an increase in APP production and Fe 65 by binding to the surface ATP synthase. Schmidt et al indicated that APP binds surface ATP synthase and that the binding sequence of APP is similar to the ATP synthase binding sequence of the inhibitor of F1, a naturally occurring inhibitor of the ATP synthase complex in mitochondria (18). A physiologically relevant negative feedback mechanism is hypothesized to be operating, closely coordinating the levels of APP expression, surface ATP synthase and $A \beta$ production. Fe65 was first shown to interact with APP in a yeast two-hybrid system (23). A previous study showed that Fe65 binds directly to the cytoplasmic domain of APP through its carboxyl-terminal-phosphotyrosine interaction domains subsequently (20). The current observations are in agreement with an important role of surface ATP synthase in $\mathrm{A} \beta$-mediated neurotoxicity and hypothesize that one of the mechanisms that play a role in the neurodegenerative processes are observed in AD. However, the surface ATP synthase trigger neuronal stress mechanisms in the presence of $\mathrm{A} \beta$ require further investigation.

\section{Acknowledgements}

The study was supported by grants from the Shanghai Health Bureau Youth Fund (no. 20114Y104) and the Innovation Program of Shanghai Municipal Education Commission (no: 09YZ118).

\section{References}

1. Kayed R, Head E, Thompson JL, et al: Common structure of soluble amyloid oligomers implies common mechanism of pathogenesis. Science 300: 486-489, 2003.

2. Fifre A, Sponne I, Koziel V, et al: Microtubule-associated protein MAP1A, MAP1B, and MAP2 proteolysis during soluble amyloid beta-peptide-induced neuronal apoptosis. Synergistic involvement of calpain and caspase-3. J Biol Chem 281: 229-240, 2006.

3. Selkoe DJ: Soluble oligomers of the amyloid beta-protein impair synaptic plasticity and behavior. Behav Brain Res 192: 106-113, 2008.

4. You H, Tsutsui S, Hameed S, et al: A $\beta$ neurotoxicity depends on interactions between copper ions, prion protein, and N-methyl-D-aspartate receptors. Proc Natl Acad Sci USA 109: 1737-1742, 2012.

5. Verdier Y,Zarándi M and Penke B: Amyloid beta-peptide interactions with neuronal and glial cell plasma membrane: binding sites and implications for Alzheimer's disease. J Pept Sci 10: 229-248, 2004.

6. Kim BW, Choo HJ, Lee JW, Kim JH and Ko YG: Extracellular ATP is generated by ATP synthase complex in adipocyte lipid rafts. Exp Mol Med 36: 476-485, 2004.

7. Burrell HE, Wlodarski B, Foster BJ, et al: Human keratinocytes release ATP and utilize three mechanisms for nucleotide interconversion at the cell surface. J Biol Chem 280: 29667-29676, 2005.

8. Champagne E, Martinez LO, Collet X and Barbaras R: Ecto-F1Fo ATP synthase/F1 ATPase: metabolic and immunological functions. Curr Opin Lipidol 17: 279-284, 2006.

9. Mowery YM and Pizzo SV: Targeting cell surface F1F0 ATP synthase in cancer therapy. Cancer Biol Ther 7: 1836-1838, 2008

10. Vantourout P, Radojkovic C, Lichtenstein L, Pons V, Champagne E and Martinez LO: Ecto- $\mathrm{F}_{1}-\mathrm{ATPa}_{\mathrm{A}}$ : a moonlighting protein complex and an unexpected apoA-I receptor. World J Gastroenterol 16: 5925-5935, 2010.

11. Xing SL, Yan J, Yu ZH and Zhu CQ: Neuronal cell surface ATP synthase mediates synthesis of extracellular ATP and regulation of intracellular pH. Cell Biol Int 35: 81-86, 2011.

12. Xing SL, Chen B, Shen DZ and Zhu CQ: $\beta$-amyloid peptide binds and regulates ectopic ATP synthase $\alpha$-chain on neural surface. Int J Neurosci 122: 290-297, 2012.

13. Magdesian MH, Carvalho MM, Mendes FA, et al: Amyloid-beta binds to the extracellular cysteine-rich domain of Frizzled and inhibits Wnt/beta-catenin signaling. J Biol Chem 283: 9359-9368, 2008.

14. Shaked GM, Kummer MP, Lu DC, Galvan V, Bredesen DE and Koo EH: Abeta induces cell death by direct interaction with its cognate extracellular domain on APP (APP 597-624). FASEB J 20: 1254-1256, 2006.

15. Fabre AC, Vantourout P, Champagne E, et al: Cell surface adenylate kinase activity regulates the $\mathrm{F}(1)$-ATPase/P2Y (13)-mediated HDL endocytosis pathway on human hepatocytes. Cell Mol Life Sci 63: 2829-2837, 2006.

16. Martinez LO, Jacquet S, Esteve JP, et al: Ectopic beta-chain of ATP synthase is an apolipoprotein A-I receptor in hepatic HDL endocytosis. Nature 421: 75-79, 2003.

17. Sergeant N, Wattez A, Galván-valencia M, et al: Association of ATP synthase alpha-chain with neurofibrillary degeneration in Alzheimer's disease. Neuroscience 117: 293-303, 2003.

18. Schmidt C, Lepsverdize E, Chi SL, et al: Amyloid precursor protein and amyloid beta-peptide bind to ATP synthase and regulate its activity at the surface of neural cells. Mol Psychiatry 13: 953-969, 2008. 
19. Guénette SY, Chen J, Jondro PD and Tanzi RE: Association of a novel human FE65-like protein with the cytoplasmic domain of the beta-amyloid precursor protein. Proc Natl Acad Sci USA 93: 10832-10837, 1996.

20. Zambrano N, Buxbaum JD, Minopoli G, et al: Interaction of the phosphotyrosine interaction/phosphotyrosine binding-related domains of Fe65 with wild-type and mutant Alzheimer's beta-amyloid precursor proteins. J Biol Chem 272: 6399-6405, 1997.

21. Ando K, Iijima KI, Elliott JI, Kirino Y and Suzuki T: Phosphorylation-dependent regulation of the interaction of amyloid precursor protein with Fe65 affects the production of beta-amyloid. J Biol Chem 276: 40353-40361, 2001.
22. Xie Z, Dong Y, Maeda U, Xia W and Tanzi RE: RNA interference silencing of the adaptor molecules ShcC and Fe65 differentially affect amyloid precursor protein processing and Abeta generation. J Biol Chem 282: 4318-4325, 2007.

23. Fiore F, Zambrano N, Minopoli G, Donini V, Duilio A and Russo T: The regions of the Fe 65 protein homologous to the phosphotyrosine interaction/phosphotyrosine binding domain of Shc bind the intracellular domain of the Alzheimer's amyloid precursor protein. J Biol Chem 270: 30853-30856, 1995. 